\section{Jovens indígenas e o ensino superior em Mato Grosso do Sul: desafios e perspectivas na busca por autonomia e respeito à diversidade*} Indigenous young people and university teaching in Mato Grosso do Sul: challenges and perspectives in the search for autonomy and respect for diversity

\author{
Antonio Hilario Aguilera Urquiza** \\ Adir Casaro Nascimento*** \\ Michely Aline Jorge Espíndola****
}

Resumo: $\mathrm{O}$ texto trata do ensino superior como novo elemento na luta por autonomia e construção de políticas de sustentabilidade dos povos indígenas de Mato Grosso do Sul. A academia passa a ser entendida por esses jovens e suas respectivas comunidades, como espaço privilegiado de diálogo e negociação entre lógicas e formas distintas de entender o ser humano e suas relações com a natureza. Por ser o território aquele que proporciona as condições necessárias a sua reprodução social, podemos entender que sustentabilidade diz respeito à dinâmica interna de trocas, em um sistema social específico, com seus padrões de qualidade de vida, incluindo conhecimentos e experiências específicas, atualizadas em um contexto de rápidas mudanças. É nesse contexto, de rápidas mudanças, inéditos desafios e complexos processos de negociação, que está inserida a universidade, percebida como espaço privilegiado de diálogos, trocas e bricolagens, favorecendo traduções e hibridismos na perspectiva intercultural e que pode fortalecer seus processos de autonomia. Esse espaço de fronteira tem possibilitado o surgimento de elementos epistemológicos, até então subalternos, promovendo reflexões teórico-metodológicas que muito têm contribuído para o desenvolvimento de novas práticas pedagógicas e estratégias de sustentabilidade, muitas vezes limitadas, porém que tentam ser coerentes com as perspectivas de futuro de cada grupo social. A base empírica deste trabalho é a experiência com acadêmicos(as) indígenas em quatro IES que desenvolvem atividades específicas
* Texto apresentado originalmente na $26^{a}$ RBA: DESIGUALDADE NA DIVERSIDADE (ABA) - Porto Seguro,

$B A$ - 1 a 4 de junho de 2008 e redimensionado com novas discussões teóricas e atualização dos dados.

** Doutor em Antropologia (Universidade de Salamanca); professor de antropologia na Universidade Federal de Mato Grosso do Sul e no Programa de Pós-Graduação em Antropologia da UFGD. E-mail:

hilarioaguilera@gmail.com

*** Doutora em Educação (UNESP); Professora da Pósgraduação em Educação da Universidade Católica Dom Bosco. Coordenadora do Observatório da Educação Indígena Guarani e Kaiowá de MS.

E-mail: adir@ucdb.br.

**** Graduada em Ciências Sociais pela Universidade Federal de Mato Grosso do Sul; mestranda em antropologia pela Universidade Federal do Rio Grande do Norte. E-mail: aline.antropologa@gmail.com
Tellus, ano 11, n. 20, p. 79-97, jan./jun. 2011

Campo Grande, MS 
com este seguimento: UFGD (Licenciatura Indígena), UFMS, UEMS e UCDB, todas ligadas ao Programa Rede de Saberes.

Palavras-chave: Jovens indígenas; Educação superior; Autonomia.

Abstract: The text handles university teaching as a new element in the struggle for autonomy and construction of policies of sustainability of indigenous peoples in South Mato Grosso. The academic world comes to be understood by these young people and their respective communities as a privileged place for dialogue and negotiation between logics and distinct forms of understanding the human being and their relationship to nature. As the territory is that which offers the necessary conditions for social reproduction, it is understood that sustainability is related to the internal dynamic of exchanges and in a specific social system, with its standards and quality of life, including knowledge and specific experiences, brought up to date in a context of rapid changes. It is in this context, of rapid changes, unprecedented challenges and complex processes of negotiation, in which the university is inserted, perceived as a privileged place for dialogues, exchanges and do-it-yourself, favoring translations and hybridisms in the intercultural perspective that can strengthen its processes of autonomy. This frontier space has made possible the emergence of epistemological elements, until now subordinate, promoting theoretical-methodological reflections that have greatly contributed to the development of new pedagogical practices and strategies of sustainability, frequently limited, but which seek to be coherent with the perspectives of the future of each social group. The empirical basis of this study is the experience with indigenous university students in four Higher Learning Institutes that develop specific activities with this segment of society: Federal University of Greater Dourados (UFGD) (Indigenous Teacher Training), Federal University of Mato Grosso do Sul (UFMS), State University of Mato Grosso do Sul (UEMS) and Dom Bosco Catholic University (UCDB), all connected to the Network of Knowledge Program. Key words: Indigenous young people; Higher learning; Autonomy.

\section{Introdução}

A cada ano torna-se mais evidente o expressivo aumento da demanda de jovens indígenas, em todo o Brasil, por educação superior. Essa é uma realidade presente também no contexto acadêmico de Mato Grosso do Sul, apesar de suas fragilidades, sendo considerado o Estado com o maior número de acadêmicos indígenas do país, mais de $600^{1}$. Se por um lado, inicialmente, eram tentativas quase individuais e heróicas, na atualidade torna-se, cada vez mais, uma opção de famílias e sociedades inteiras, que veem na universidade uma ferramenta útil e estratégica para o futuro desses povos. Por outro lado, esse acesso até alguns anos atrás, restringia-se às licenciaturas, tendo em vista as exigências da Lei de Diretrizes e Bases da Educação (LDB, lei n. 9394/96) a qual exige a formação de professores em geral, incluindo os indígenas (cf.

${ }^{1}$ Conforme relatório do 2o Levantamento do Programa Rede de Saberes, 2009. 
Brand e Nascimento, 2008, p. 125). Como veremos mais abaixo, esse acesso atualmente expande-se por diversas Instituições de Ensino Superior do Estado (IES) e pelos mais diversos cursos de graduação.

Estar em uma Universidade implica, para estes jovens, vários processos (vestibular, transporte, alimentação, moradia, gastos extras com apostilas e livros, mudança nas relações sociais, entre outros), envolvendo diversas pessoas, particularmente a família extensa, a sua rede de parentela nas cidades de acolhida, cuja base quase sempre está localizada nas aldeias.

Esses jovens que cada vez mais demandam por acesso às universidades são originários de povos que, em geral, enfrentaram e enfrentam uma longa e histórica luta contra a exclusão e o preconceito, fato que marca a sua relação com o entorno regional. É nesse contexto que iremos refletir sobre os jovens indígenas e o ensino superior no Estado de Mato Grosso do Sul: as lutas por autonomia, os processos de adaptação, a construção de políticas de sustentabilidade e as relações interétnicas no interior desses novos espaços.

\section{Os jovens indígenas e o ensino superior em Mato Grosso do Sul}

Embora seja o Estado que possua a menor proporção de terra para os indígenas, Mato Grosso do Sul possui a segunda maior população indígena do país, ao redor de 70 mil pessoas, das etnias Guarani-Kaiowá, GuaraniÑandeva, Kadiwéu, Kiniquinau, Guató, Ofaié, Terena e Atikum (este último, originalmente de Pernambuco). A realidade cotidiana desses grupos vem marcada por duas características relevantes: a perda territorial e correspondente confinamento em terras indígenas reduzidas, com os recursos naturais profundamente comprometidos; e a intensa inserção no entorno regional, com ênfase nos espaços urbanos.

As Instituições de Ensino Superior (IES) no Estado também refletem e têm contribuído para a reprodução de um quadro regional de exclusão e discriminação dos indígenas. Por outro lado, nessas mesmas instituições existem projetos e atividades, como as Licenciaturas Indígenas ${ }^{2}$ e o Programa Rede de Saberes $^{3}$, que tem contribuído para respostas parciais a algumas demandas

\footnotetext{
${ }^{2}$ Trata-se, inicialmente, da Licenciatura Guarani (TEKO ARANDU), construída por equipe multidisciplinar e interinstitucional ao longo de vários anos e, tendo como protagonistas do processo um grupo de representantes dos professores Guarani e Kaiowá de Mato Grosso do Sul, juntamente com a UFGD (Universidade Federal da Grande Dourados) e a UCDB (Universidade Católica Dom Bosco).

${ }^{3}$ REDE DE SABERES - permanência de indígenas no ensino superior. Trata-se de um programa financiado pela Fundação Ford (em nível nacional chama-se TRILHAS DO CONHECIMENTO), e que reúne uma parceria entre a UCDB e a UEMS (a partir de 2008 passam a fazer parte a UFGD e UFMS, vigente desde final de 2005.
}

Tellus, ano 11, n. 20, jan./jun. 2011 
importantes dos acadêmicos indígenas nos últimos anos. Esses apoios, embora limitados, são percebidos pelos próprios acadêmicos indígenas como de grande relevância política porque, somados ao seu empenho pessoal e coletivo, têm permitido resultados significativos.

Tendo em vista que no Brasil ainda são incipientes as políticas públicas destinadas a atender aos anseios de autonomia dos indígenas, as comunidades indígenas passam a considerar as universidades que as acolhem (que buscam fazer o exercício de acolher a diferença) como um "terceiro espaço", ou seja, ambiente de negociações e reafirmações identitárias, de discussão de projetos de autonomia e, inclusive, de maior visibilidade. As universidades tornam-se, nesse cenário, a possibilidade real de aliados, seja na busca de novas alternativas para a gestão de seus territórios, ou mesmo para a implementação da educação indígena desejada por cada povo.

Nesse contexto, López (2005, p. 11) afirma que,

Les ha permitido tomar conciencia de la posibilidad de considerar formas de reencontrarse consigo mismos y de, al menos, imaginar alternativas educativas que den cuenta de su condición diferente y diferenciada dentro del contexto.

Na percepção de muitas lideranças indígenas do Estado, as universidades podem ser espaços privilegiados para o diálogo e o encontro de culturas, deixando de lado o período em que essas mesmas instituições eram consideradas como espaços de reprodução da exclusão e do preconceito contra os povos indígenas. Nesse sentido, o acesso ao ensino superior pode servir como ferramenta para superar as tentativas/tendências do Estado brasileiro para a homogeneização das práticas culturais, visando, assim, incentivar processos de autonomia regional e políticas de sustentabilidade dos povos indígenas. 127), que:

Nesse sentido podemos dizer, conforme Brand e Nascimento (2008, p.

Sob a ótica dos povos indígenas, as experiências em andamento confirmam que a educação superior pode contribuir, significativamente, para criar melhores condições de sustentabilidade e autonomia das populações indígenas no Brasil. Exige, porém, das Universidades, repensarem suas metodologias de ensino e questionamento do saber historicamente sedimentado, a partir da visão de mundo ocidental.

Ao ampliar e fortalecer a presença dos acadêmicos indígenas em cada instituição universitária, estimulando a sua participação em todas as atividades acadêmicas e de extensão, desenvolvidas no âmbito das mesmas instituições, esses projetos e ações abrem brechas importantes, especialmente na perspectiva do diálogo de saberes, superando e indo além, inclusive, da limitada, embora socialmente relevante, perspectiva da inclusão, sinalizado pelas políticas de cotas (Brand; Nascimento, 2008, p. 127). 
Em uma perspectiva histórico-processual, podemos afirmar que em todo o Centro-Oeste, mas de modo particular no Estado de Mato Grosso do Sul, os povos indígenas estiveram e estão no meio do caminho da política expansionista do Estado Brasileiro, que se concretizou, inicialmente, através da violenta expansão da frente de colonização, conhecida como "marcha para o oeste". Já mais recentemente, na década de 1970, os povos indígenas se confrontaram com a monocultura da soja e consequente mecanização da atividade agrícola. E, nesse momento, com a expansão dos canaviais, que vão cercando aldeias e casas. Nesse processo, o comprometimento dos recursos naturais, resultante da perda da terra, retirou as condições necessárias para o exercício da economia tradicional, impondo aos homens indígenas o assalariamento. Provocou a rápida passagem de alternativas variadas de subsistência - agricultura, caça, pesca e coleta - para uma única alternativa, a agricultura, e esta apoiada em poucas variedades de cultivares, e, mais recentemente, o assalariamento em usinas de álcool e açúcar'; situação que tende a mudar nos próximos anos, com a mecanização do corte de cana, jogando, por outro lado, milhares de indígenas para a informalidade. No entanto, mais do que as alternativas econômicas, essa situação vai comprometendo, de forma crescente, a autonomia interna desses povos por reduzir suas possibilidades de decisão sobre essas questões, deixando cada vez um espaço mais reduzido para a negociação a partir de suas alternativas histórico-culturais. É nesse contexto que essas populações vêm buscando, de forma crescente, o ensino escolar básico e, mais recentemente, aumenta a demanda pelo acesso ao Ensino Superior nas Universidades, como ferramenta que pode ajudá-los a enfrentar o futuro incerto.

\section{Os jovens indígenas no cotidiano das IES em Mato Grosso do Sul}

Desde o final da década de 1980 que alguns indígenas, notadamente do povo terena, por esforços próprios e fundamental apoio das famílias e, em alguns casos, de lideranças, conseguiram romper com as barreiras de acesso ao ensino superior no Estado de Mato Grosso do Sul. Quase sempre na área da pedagogia, alguns poucos conseguiram titulação, condição necessária para participar mais efetivamente do "serviço público".

Após a Constituição Federal de 1988 e o reordenamento jurídico, particularmente referente à Educação Indígena e ao respeito à cultura (línguas, territórios, etc.), houve novo impulso, por parte dos povos indígenas, em especial, os jovens, na procura de espaços nas universidades, demanda que vem aumentando a cada ano.

\footnotetext{
${ }^{4}$ Cerca de 400 homens, da Área Indígena Te'ýikue de Caarapó, por exemplo, trabalham a maior parte dos meses do ano nas usinas de produção de açúcar e álcool, através de contratos de trabalho de 60 dias ou mais.
} 
Conforme Souza Lima e Hoffmann (2004, p. 171), "há dois vieses diferentes, mas historicamente entrelaçados, que têm sido percebidos de modo separado e que, todavia, confluem na busca dos povos e organizações indígenas por formação no ensino superior". Os dois vieses a que os autores se referem são: a busca por cursos de formação específica para professores indígenas e a procura por capacitação para gerenciar seus territórios e os desafios de um novo cenário de interdependência entre os povos indígenas e o Estado no Brasil. Essas principais demandas estão presentes entre as etnias deste Estado.

Seguem abaixo alguns dados elaborados no âmbito do Programa Rede de Saberes. A equipe desse Programa realizou, nos anos de 2006 e 2009, um detalhado levantamento ${ }^{5}$ sobre o perfil do acadêmico indígena nas IES de Mato Grosso do Sul, na certeza de que quanto melhor se conhecer a realidade desses acadêmicos, melhores serão as condições para dialogar com eles e prestar-lhes o apoio necessário. Na sequência, alguns gráficos mais relevantes, seguidos dos respectivos comentários.

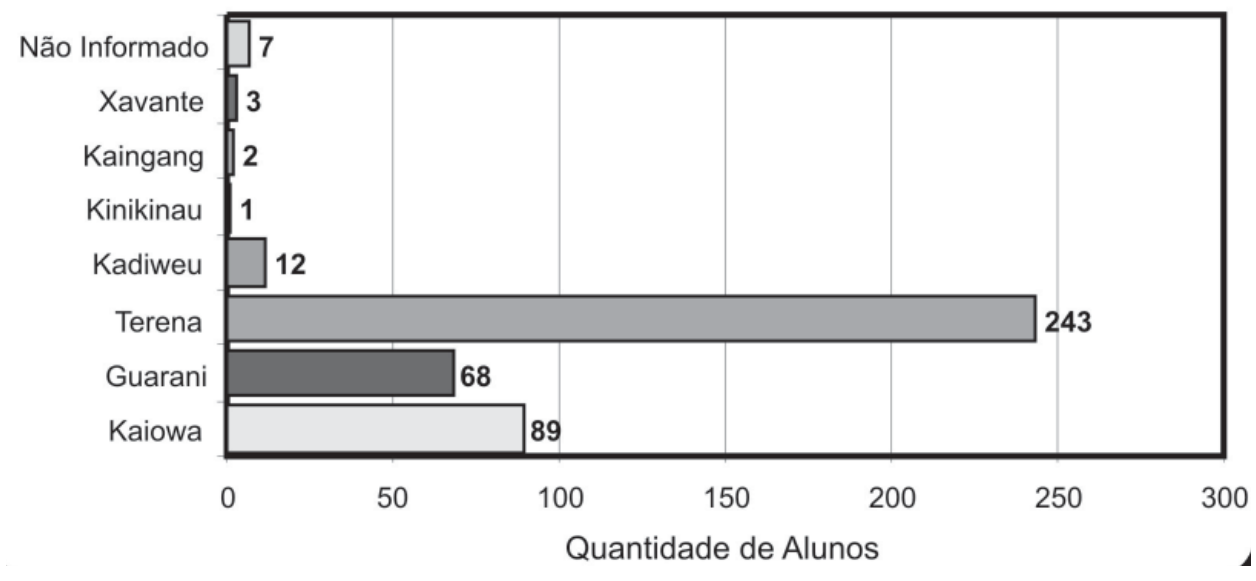

Quadro 1 - Acadêmicos(as) indígenas por povo em MS / $2009^{6}$

Fonte: Levantamento do programa "Rede de Saberes" - UCDB, 2009

Com relação ao ensino superior, embora já diversos indígenas sejam portadores de títulos de conclusão de curso de ensino superior, resultado de

\footnotetext{
${ }^{5}$ Foi elaborado questionário socioeconômico (procedência, tipo de moradia, rendimento, tamanho da família, etc.) e com questões sobre elementos culturais: etnia, língua (se é falante ou não), perspectiva de futuro, etc. Este questionário foi entregue à quase totalidade dos acadêmicos indígenas matriculados nas várias IES do Estado. Tanto em 2006 quanto em 2009, houve um universo de pouco mais de $70 \%$ de questionários devolvidos, resultado suficiente para uma amostragem deste universo.

${ }^{6}$ Neste quadro e nos próximos, a totalização refere-se ao número dos questionários respondidos e não ao universo dos(as) acadêmicos indígenas do Estado de Mato Grosso do Sul.
} 
condições socioeconômicas pessoais ou familiares, o acesso e a permanência dos povos indígenas nas IES foi tema fora da agenda das políticas públicas por parte dos governos Federal e Estadual. Somente a partir 2002, a UEMS instituiu uma política de acesso diferenciado (cotas de 15\% para afrodescendentes e $10 \%$ para indígenas) e de bolsas para esse importante segmento no Estado de Mato Grosso do Sul.

$\mathrm{Na}$ atualidade percebe-se que, em todas as Áreas Indígenas do Estado, cresce o interesse das comunidades e de suas lideranças pelo estudo de seus jovens, percebendo as universidades como um novo espaço estratégico relevante em sua luta por melhores condições de vida e maior autonomia. Como consequência dessa recente demanda, o Estado de Mato Grosso do Sul possui, na atualidade, mais de 600 acadêmicos(as) indígenas nas várias IES, sendo que o maior grupo frequenta a UEMS, situando-se como o Estado brasileiro com a maior quantidade de indígenas no Ensino Superior.

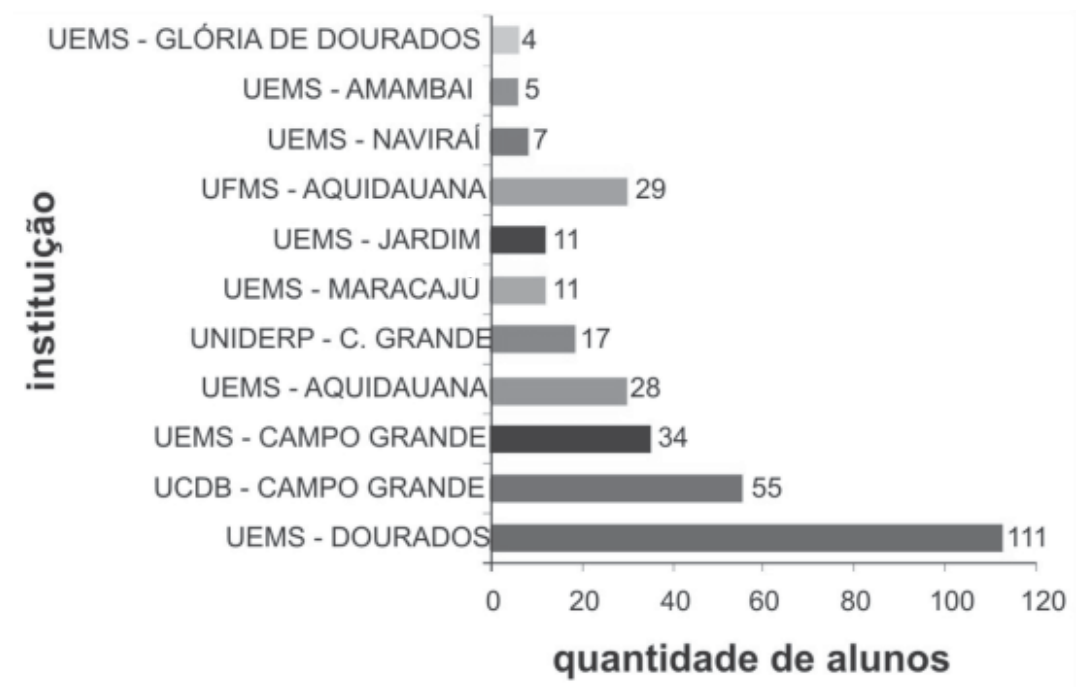

Quadro 2 - Acadêmicos(as) indígenas por IES em MS / 2006

Fonte: Levantamento do programa "Rede de Saberes" - UCDB, 2006

Entendemos que não bastam políticas afirmativas ou de acesso ao ensino superior, mas é necessária a aplicação de "novos paradigmas educativos que estimulam a necessidade de articular a ciência ocidental com os conhecimentos ancestrais dos povos indígenas e grupos étnicos" (Grümberg, 2005), com o objetivo de possibilitar a capacitação, formação e profissionalização desses novos recursos humanos. Podemos dizer que as Universidades, através do acompanhamento de processos de autogestão e sustentabilidade entre os estu- 
dantes indígenas e suas comunidades, estariam, de certa forma, contribuindo para o fortalecimento do processo de autonomia dos povos indígenas desta região sul-mato-grossense.

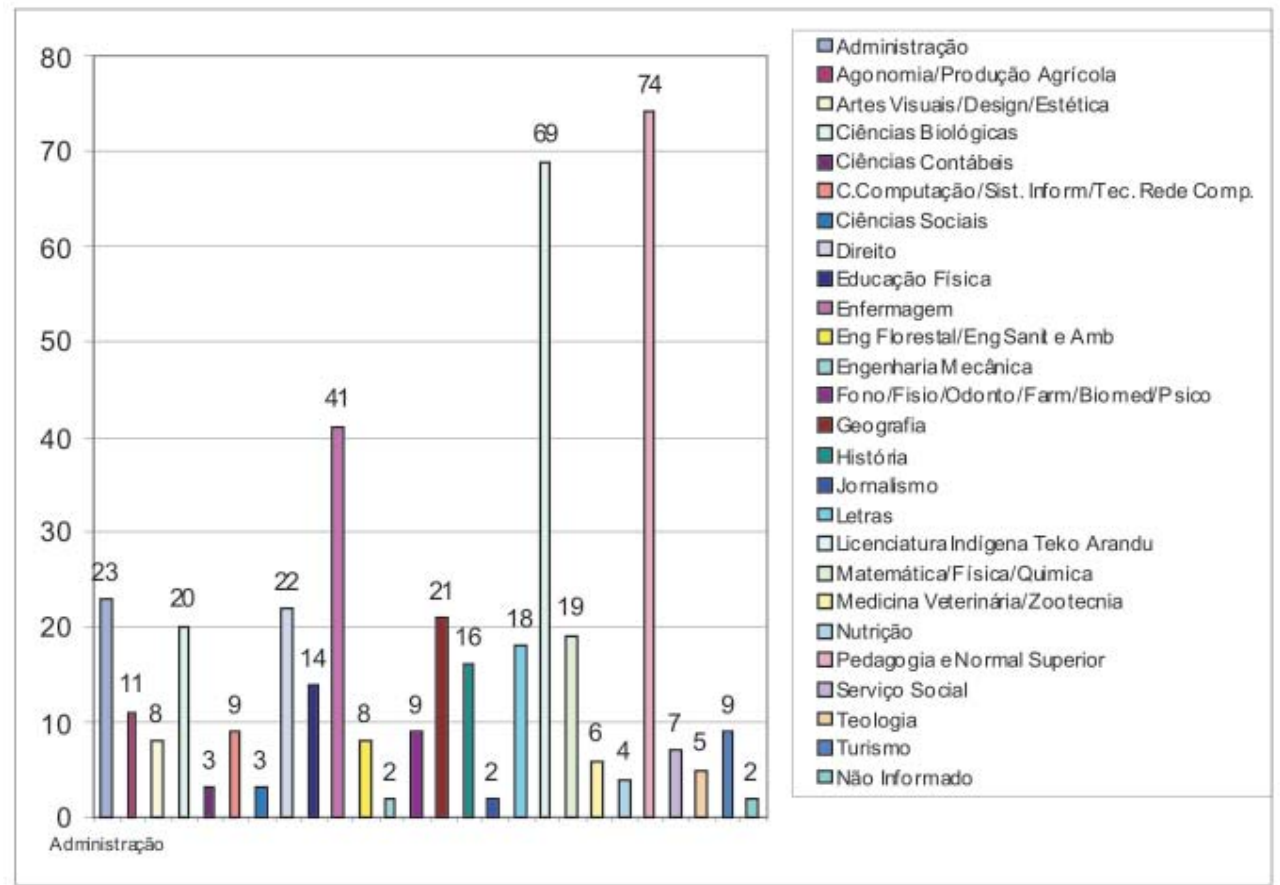

Quadro 3 - Acadêmicos(as) indígenas por curso nas IES de MS em 2009

Fonte: Levantamento do programa “Rede de Saberes" - UCDB, 2009.

Constata-se, a partir do quadro acima, que a maior demanda entre os estudantes indígenas ainda é pela formação docente, ou seja, o curso "Normal Superior", que forma para o exercício do magistério nas aldeias. No entanto essa realidade passa por rápida mudança, pois já cresce a procura por outras áreas, como a de saúde, direito e agrárias (agronomia, administração rural, Zootecnia, entre outras).

O que se busca, na verdade, em médio prazo, é a questão da autonomia dos povos indígenas, e a educação mostra-se como uma das possibilidades dessa conquista. Por outro lado, é importante ressaltar que esse dinâmico e às vezes contraditório processo de busca de autonomia, presente nas lutas e ações coletivas, é protagonizado por povos que eram, historicamente, autônomos, desenvolvendo para isso complexas e variadas relações de troca, de aliança ou mesmo de guerra com os outros povos. No presente, a afirmação da autonomia de cada povo continua relacionada diretamente às possibilida- 
des (e a dos povos indígenas em geral) em alterar as relações, historicamente estabelecidas com o entorno regional. E, nesse sentido, essa população segue recorrendo a complexas e variadas relações de negociação e tradução ${ }^{7}$, processos nem sempre perceptíveis aos atores sociais. E aí, o espaço escolar/ universitário vem se constituindo como lugar privilegiado para a dinamização e compreensão desses processos.

É sob o prisma da autonomia que se articulam e criam sentido, de um lado, as grandes lutas pela necessária ampliação territorial e, de outro, as demandas por um ensino específico e de qualidade, incluindo o acesso à Universidade, a busca de participação nos espaços de representação e decisão da sociedade não-indígena, como os poderes legislativos e executivos, entre outros (Brand, 2006).

Nesse sentido, a educação vem se constituindo em demanda importante na luta pelos direitos dos povos indígenas no Brasil e, em particular, no Mato Grosso do Sul. A partir das práticas concretas de educação indígena nas últimas décadas, já é possível perceber a influência da visão culturalmente diferenciada desses povos, a força que suas práticas rituais e míticas exercem, influenciando, de certo modo, até mesmo as propostas curriculares. Assim, o respeito às formas de pedagogia endógenas (processos próprios de aprendizagem), o uso dos seus idiomas, a formação e capacitação de professores indígenas e até mesmo a elaboração de materiais didáticos culturalmente aceitáveis, são algumas das bandeiras e desafios para as universidades.

Nesse sentido, alerta Oliveira Filho (2004) para o fato de que não se trata apenas de uma questão de inclusão social, mas sim da construção de uma outra universidade: "O problema das populações indígenas no que se refere ao ensino superior não é de baixa escolaridade, mas do reconhecimento e promoção de valores e visões de mundo diferenciados [...] e ao empoderamento das sociedades".

\section{Os desafios para os jovens indígenas e para o ensino superior}

Podemos elencar, na sequência, e discutir acerca de alguns desafios claramente presentes nesse acesso, cada vez mais amplo, dos povos indígenas em

\footnotetext{
${ }^{7}$ Ao analisar os processos pós-coloniais, Bhabha (1998) recorre ao conceito de negociação para buscar superar as visões dualistas, que opõe, simplesmente, dominador e dominado, centroperiferia, rico-pobre, branco-negro, entre outros, chamando a atenção para as estruturas de interação, presentes entre os dois, buscando articular elementos antagônicos e opostos, porém, sem a pretensão da sua superação dialética. A negociação sinaliza para um processo que não se identifica com nenhum dos dois polos, mas algo mais que contesta e vai além de ambos. Pompa (2003), de maneira semelhante, recorre ao conceito de tradução para explicar as complexas relações que se estabelecem entre povos com visões de mundo tão distintas.
}

Tellus, ano 11, n. 20, jan./jun. 2011 
direção aos espaços acadêmicos. Um primeiro diz respeito a sua presença na Universidade e às dificuldades desta em dialogar com esses povos, situados em outra tradição cultural, com saberes e processos sociais e históricos diferenciados. Nesse sentido, podemos elencar as questões relacionas a práticas de discriminação (funcionários, colegas que evitam participar de grupos de estudos/trabalhos com acadêmicos indígenas), dificuldades de compreensão dos códigos acadêmicos (linguagem, leitura e compreensão de textos, expressão oral), burocracia acadêmica (documentos, prazos), entre outros.

Um segundo problema pode ser assim explicitado: como transitar em direção a uma educação mais engajada nos problemas diários vivenciados pelos povos indígenas, nos quais se destacam problemas relacionados aos seus territórios, recursos naturais e à reconstrução de condições de sustentabilidade, ou, ainda, problemas decorrentes de relações profundamente assimétricas, marcadas e corroídas pelo preconceito contra seu modo de vida? Como transformar, nesse contexto, o espaço escolar, em especial o acadêmico, em espaço de trânsito, troca e articulação de saberes e alternativas em uma população que se confronta com inúmeros desafios novos? Nesse sentido, o Programa Rede de Saberes busca pequenos espaços na estrutura das IES, para articular, por exemplo, os acadêmicos indígenas da área do direito, propondo momentos de estudo (curso de especialização), intercâmbio com outras realidades, envolvimento de lideranças das aldeias, sugestão de inclusão do tema do direito indígena na grade do curso de direito das IES/MS.

Um terceiro desafio diz respeito à situação pós-academia, ou seja, o que fazer depois de concluída a trajetória acadêmica. No caso de Mato Grosso do Sul, a situação de conflito aberto entre índios e fazendeiros pela posse da terra, agravada por uma relação histórica de exclusão e negação da cultura indígena, manifestada pelos preconceitos que perpassam a relação com o entorno regional, dificulta a relação do recém formado com o mercado de trabalho. Como evitar que a passagem pelas IES não se traduza amanhã em nova frustração, quando, concluído o curso, não encontrarem trabalho ou, em outros termos, seguirem sem lugar na realidade regional?

Além desses desafios mais estruturais, constatamos que a presença indígena nas IES tem provocado uma tensão no espaço acadêmico, no sentido de considerar o conhecimento a partir da diferença, de outras lógicas epistemológicas que não a produzida pela cultura ocidental e imposta como condição única de compreensão e concepção de mundo. Isso gera instabilidades de cunho epistemológico e metodológico que dão consistência aos desafios de pensar relações tais como: culturas locais, culturas híbridas e globalização; o território acadêmico com as diversas formas de produção de conhecimento; a academia e a produção de conhecimento sobre as diferenças; a universidade como espaço público requisitado pelos índios como garantia de 
sustentabilidade étnica e de reelaboração de conhecimento a partir de lógicas de compreensão de mundo, como âncoras para a produção de alternativas de sustentabilidade econômica.

Se, por um lado, nenhum outro segmento da população brasileira foi capaz de, pela sua presença identitária, provocar a necessidade da universidade rever a sua estrutura, a sua própria identidade no atendimento ao trabalho do pensamento que respeite as diversas lógicas e cosmovisões vindas da sociedade ou sociedades que a abriga, por outro lado, no entanto, mudanças estruturais no modelo tradicional e centenário de universidade não são, certamente, fáceis e de curto prazo. Porém, ao ampliar e fortalecer a presença dos acadêmicos indígenas em cada instituição universitária, estimulando sua participação em todas as atividades acadêmicas e de extensão, desenvolvidas no âmbito das mesmas instituições, esses projetos e ações abrem brechas importantes, especialmente na perspectiva do diálogo de saberes.

Outro aspecto relevante para as aspirações dos povos indígenas é a crescente articulação entre as Universidades, os acadêmicos indígenas e as suas respectivas comunidades, através da participação direta de suas lideranças. Não se trata apenas de universalizar a escolarização genericamente para cumprimento do direito prescrito pela legislação ou pelos acordos internacionais, mas de cobrar do Estado políticas de formação de indígenas altamente qualificados e comprometidos com a defesa dos seus direitos, em especial com a promoção da qualidade de vida das suas comunidades de origem, o que inclui, inevitavelmente, a gestão dos territórios e o fortalecimento de suas organizações.

Surge, dessa maneira, um novo desafio para as próprias IES do Estado: que outra universidade deve servir aos povos indígenas e qual a sua função? Ou seja: que proposta político-pedagógica deve nortear a universidade capaz de construir currículos e práticas pedagógicas que sustentem as tensões e os conflitos entre as culturas para que a diferença seja respeitada? Exige-se das universidades repensarem suas metodologias de ensino, superando a fragmentação e questionando o saber academicamente sedimentado, que perpassa e está subjacente em nossas práticas pedagógicas, objetivando o exercício constante da interculturalidade. Exige-se das universidades, cumprindo o que determina a Constituição/88 e a Lei de Diretrizes e Bases 9394/96, criarem mecanismos que as consolidem como instituições plurais, multiétnicas. Exige-se das universidades novos saberes, novos fazeres (Nascimento, 2006).

O que os povos indígenas buscam, no ensino superior, é, na verdade, a possibilidade de fortalecer os próprios conhecimentos indígenas, reelaborar mecanismos de produção e negociação de conhecimentos para que possam gerir seus territórios, planejar e desenvolver projetos em proveito de suas comunidades. Em outras palavras, responder positivamente aos desafios e perspectivas que se colocam a esses povos, na busca por autonomia e respeito 
à diversidade, a partir do contexto do ensino superior, espaço, por um lado, propício ao diálogo e trânsito de ideologias e novas propostas sociais e, por outro, o lócus privilegiado de formação das novas gerações de lideranças sociais do país.

Esse processo de ocupar espaços nas IES, particularmente no caso do Estado de Mato Grosso do Sul, entretanto, tem gerado muitas reações por parte da comunidade acadêmica, em um cotidiano repleto de contraditórias relações interpessoais.

\section{Busca por autonomia e respeito à diversidade}

Na tentativa de explicitar melhor a presença dos acadêmicos indígenas na universidade, segue a reflexão/depoimento de Karine Silva Sobrinha, da etnia terena, atualmente cursando Pedagogia na Universidade Estadual de Mato Grosso do Sul (UEMS).

Nós indígenas consideramos e aspiramos à academia como um instrumento articulado, para a fomentação de diálogo, abertura de discussões sobre diversos saberes, além de fornecer subsídio para fortalecer nossa identidade cultural diante de inúmeras especificidades ocidentais (podemos ser igual a você sem deixar de ser quem sou). Entendemos que fora de nossas aldeias estamos engajados em uma luta individual que direta ou indiretamente proporcionará benefícios a nossa comunidade.

Tive o privilégio de participar da implantação do programa Rede de Saberes na qualidade de acadêmica (UCDB 2005) tendo todo o respaldo garantido enquanto suporte acadêmico laboratório de informática, internet, xérox, biblioteca, além da imprescindível valorização da cultura que o programa oportunizou. Sabemos que esse é um grande marco educacional dentro da óptica educação escolarizada, pois por séculos tivemos nossa identidade sufocada e exterminada, oriunda do período colonial, um grande exemplo disso é o relato de meu avô:

"Quando ia para escola, não sabia falar o português nem eu nem meus patrícios ainda kalivonó, quando íamos ao banheiro se não pedíssemos em português não podíamos ir". (Tibúrcio Sobrinho).

Compreendo que estamos caminhando nessa reorganização de autonomia, e participo desse momento histórico. Não concluí meu curso, inicialmente por motivos pessoais, além de perder a bolsa da FUNAI primordial para a continuação do curso. No final de 2008, me candidatei para o vestibular da Universidade Estadual de Mato Grosso do Sul, unidade de Campo Grande, curso Pedagogia, instituição gênese do sistema de cota no estado, passei em primeiro lugar e, atualmente, estou cursando o 20 ano.

Essas lacunas abertas pelas universidades garantem e incentivam nossa busca pelo ensino superior, uma maneira de garantir nossos direitos, 
dentre eles o vital o de sermos índios, podendo compartilhar saberes com não índios e assegurar por intermédio da educação garantia de nossos territórios, cultura e saúde mantendo nossa identidade.

No depoimento ficam patentes as dificuldades dos indígenas em permanecer no ensino superior, mas, sobressai, especialmente, a percepção da importância da educação para a busca da autonomia e reconhecimento da diversidade desses povos e o direito a manter seus traços identitários, mesmo no contexto "anti-indígena" deste Estado.

Um aspecto importante na percepção das reações que a universidade vem tendo com a presença indígena são as práticas descritas aqui, pela professora Beatriz Landa ${ }^{8}$, Coordenadora do Programa Rede de Saberes na Universidade Estadual do Mato Grosso do Sul (UEMS) e, na sequência, o depoimento de outros estudantes indígenas de algumas IES.

A Universidade oferece o sistema de cotas e tem, neste ano, o expressivo número de quase 200 acadêmicos indígenas distribuídos em nove Campi. Nos últimos 5 anos de processo de seleção, a presença dos acadêmicos indígenas trouxe uma grande novidade que interferiu na dinâmica da instituição. Nesse sentido, Landa aponta como aspectos positivos:

- o despertar do interesse por parte de alguns profissionais (dos serviços gerais aos docentes e administração) em apreender essa diferença desenvolvendo novas formas de abordagens tendo em vista o Outro como portador de conhecimentos e culturas diferentes.

- a tomada de defesa, posicionar-se, tomar partido em favor dos indígenas e os seus direitos de uma educação específica e diferenciada.

- embora possa parecer negativo em um primeiro momento, o impacto que a percepção da diferença no contexto acadêmico tem causado.

- por parte dos índios, a possibilidade que o sistema de cotas oferece de escolher os cursos dentro da instituição podendo ampliar os serviços qualificados dentro da aldeia.

Como elementos de conflito e/ou de desconforto, o mesmo relato aponta que:

- os referenciais construídos sobre os índios, a partir de um imaginário altamente etnocêntrico e que gera imagens equivocadas: o índio como um ser exótico, folclórico, da selva, da caça e da pesca, dos adornos, das penas. O índio com uma identidade congelada.

- o índio não associado ao conhecimento no contexto do paradigma ocidental. Retira-se do índio o potencial para assimilação e produção do conhecimento.

\footnotetext{
${ }^{8}$ Informações obtidas, através de entrevista, com a Profa. Dra. Beatriz Landa (2009), Coordenadora do PROGRAMA REDE DE SABERES na Universidade Estadual do Mato Grosso do Sul (UEMS).
} 
- o tratamento diferenciado como um privilégio e neste sentido negros e índios estão ocupando o lugar do branco indevidamente, ou seja, ocupam o lugar daquele que tem o potencial apropriado: o saber da academia.

- o insucesso do aluno índio é potencializado, não tem a mesma interpretação que se dá ao insucesso do aluno não-índio. $\mathrm{O}$ acadêmico não-indígena tem insucesso porque vem de uma formação precária; o acadêmico indígena tem insucesso porque é incapaz.

- a relação entre acadêmicos, em que, grosso modo, há uma nítida diferença entre os cursos considerados nobres - direito, agrárias - que discriminam e os cursos de licenciatura que apresentam mais facilidade de interação.

- com relação à burocracia, os acadêmicos indígenas que não tiveram acesso por meio de cotas ou de projetos especiais não são visíveis nos dados da instituição.

- e por fim, a política da universidade desconsiderava/desconsidera as identidades étnicas do Estado e com isso constrói todo um aparato legal, técnico, burocrático e pedagógico como se não houvesse diferenças em seu território de ação.

Mais uma vez, fica patente que o simples acesso à educação superior não é o suficiente para garantir mudanças estruturais nas IES e na sociedade, pois os saberes indígenas permanecem à margem dos conteúdos curriculares e, o pior, ao formar também os jovens indígenas, corre o risco de fazê-lo, na categoria de "novos intelectuais" totalmente desconectados ou descomprometidos com a realidade de seus povos.

Dessa forma, não temos ilusão de que a simples presença em massa de acadêmicos indígenas no Ensino Superior signifique mudanças qualitativas para seus respectivos povos. Isso demanda a busca por mudanças internas nas universidades, assim como a luta por políticas que garantam a permanência nas IES e respeito aos projetos de autonomia e sustentabilidade.

De outra parte, é importante atentar para a dimensão de busca de autonomia, presente nas lutas e ações coletivas das populações indígenas no contexto pós-colonial. Tratamos com povos que eram, historicamente, autônomos, desenvolvendo, para isso, complexas e variadas relações de troca, de aliança ou mesmo de guerra com os outros povos. No presente, a afirmação da autonomia de cada povo continua relacionada diretamente às suas possibilidades (e à dos povos indígenas em geral) em alterar as relações estabelecidas com o entorno regional. E, para isso, segue recorrendo a complexas e variadas relações de negociação e tradução. E aí, o espaço escolar vem se constituindo como lugar privilegiado para a efetivação desses processos. Entendemos que é sob o prisma da autonomia que se articulam e criam sentido, de um lado, as grandes lutas pela necessária ampliação territorial e, de outro, as demandas por um ensino de qualidade. Isso inclui o acesso à Universidade, a busca de 
participação nos espaços de representação e decisão da sociedade não-indígena, como os poderes legislativos e executivos, entre outros.

Acreditamos, dessa forma, que a presença indígena na universidade, como formadora de atitudes interculturais, parece ser o acontecimento emergente para que possamos tornar a sociedade atual mais traduzível, em meio às suas diferenças, e liberar as práticas acadêmicas do compromisso de representar uma só identidade.

Outro conceito importante aos povos indígenas e que se relaciona intimamente com a presença dos jovens nas IES, é o de autonomia, entendido, aqui, conforme Brand (1999), no contexto da Constituição de 1988, na qual se encontra uma série de dispositivos relacionados ao reconhecimento dessa autonomia. Destacam-se, entre esses dispositivos, o reconhecimento da organização social, costumes, línguas, crenças e direitos originários sobre as terras que tradicionalmente são ocupadas pelos povos indígenas. Ao reconhecer e determinar o respeito à organização social e às terras de cada povo, o texto constitucional restringe $\mathrm{a}$ ação do Estado à garantia desses direitos.

Nesse contexto se encontram, também, os limites legais da autonomia dos povos indígenas. Evidentemente que cada povo interpretará e atribuirá dimensões específicas ao termo em epígrafe, em função de sua cultura e de sua experiência histórica de enfrentamento do entorno regional, donde decorrem em grande parte, hoje, suas expectativas de futuro. Entendemos, assim, por entorno regional, aqueles setores da sociedade nacional que se situam e/ou têm interesses específicos junto às comunidades indígenas ou, ainda, que são objeto de interesse por parte das mesmas comunidades. Incluem-se aqui órgãos públicos, igrejas, mídia, proprietários residentes nesse entorno e outros. Não se trata, portanto, de um conceito geográfico, mas relacional. O conceito de autonomia é, hoje, para os povos indígenas, um conceito em construção e diretamente relacionado à luta de cada um deles. A sua abrangência concreta depende exatamente da ampliação das perspectivas históricas de luta de cada povo. Por isso a compreensão do conceito nos remete para o necessário estudo de sua cultura, de sua história e das perspectivas frente ao entorno regional.

É importante salientar que esse processo de construção de autonomia passa, inevitavelmente, pela questão dos territórios, entendidos como construção resultante do "esforço coletivo de um grupo social para ocupar, usar, controlar e se identificar" com determinada parcela do ambiente físico (Little, 2002, p. 3). Remete, portanto, para as situações e "contingências históricas", vivenciadas pelos povos indígenas.

É nesse contexto que se insere o acesso dos povos indígenas ao ensino superior. Como, no entanto, ir além desse simples acesso às universidades, reconhecendo que se trata de povos situados em outra tradição cultural, com saberes e processos sociais e históricos diferenciados? Como transitar em 
direção a uma educação mais engajada nos problemas diários vivenciados pelos povos indígenas, nos quais se destacam problemas relacionados aos seus territórios, recursos naturais e à reconstrução de condições de sustentabilidade, ou, ainda, problemas decorrentes de relações profundamente assimétricas, marcadas e corroídas pelo preconceito contra seu modo de vida? Como transformar, nesse contexto, o espaço escolar, em especial o acadêmico, em espaço de trânsito, troca e articulação de saberes e alternativas em uma população que se confronta com inúmeros desafios novos?

Finalizamos estas reflexões com alguns depoimentos de acadêmicos(as) indígenas: dois deles após terem vivido a experiência com o Programa Rede de Saberes, o depoimento do Eliel Benites (professor indígena, acadêmico da Licenciatura Teko Arandu, e retomamos a parte inicial do depoimento da acadêmica Karine.

À pergunta sobre o que significou passar pelo Ensino Superior e participar do Programa Rede de Saberes, os acadêmicos responderam:

Esse Programa foi uma grande esperança de concluir a graduação e, sobretudo, esperança para os próximos indígenas que estarão chegando nos anos seguintes à universidade. As dificuldades são muitas, e o Programa Rede de Saberes nos ajudou muito no apoio pedagógico e também com as pesquisas, dando incentivo para o estudo e permanência. (Edineide Bernardo Farias/Terena - curso de Letras - UCDB).

Para mim está sendo como uma grande ajuda para que eu possa terminar o meu curso. Tem dado total apoio nos estudos e atividades acadêmicas. Minha família está contente, e inclusive meu pai tem acompanhado várias reuniões do Rede de Saberes na Universidade. Depois de vários cursos de extensão e complementação, tutorias, e apoio à pesquisa, posso dizer que atualmente tenho muito mais experiência e que a universidade ganhou outro significado para mim e para meu povo (Antonio Fernandes Bernardo/Terena - curso de Geografia - UCDB).

É preciso afirmar a nossa visão, para, dessa forma, fortalecer a nossa cultura e nosso povo. [...] Se não soubermos quem somos, não poderemos atingir o desenvolvimento e o fortalecimento de nossa cultura e de nossa língua. (Eliel Benites/Guarani-Kaiowá - professor e alunos da Licenciatura Teko Arandu - UFGD).

Nós indígenas consideramos e aspiramos à academia como um instrumento articulado, para a fomentação de diálogo, abertura de discussões sobre diversos saberes, além de fornecer subsídio para fortalecer nossa identidade cultural diante de inúmeras especificidades ocidentais (podemos ser igual a você sem deixar de ser quem sou). Entendemos que fora de nossas aldeias estamos engajados em uma luta individual que direta ou indiretamente proporcionará benefícios a nossa comunidade. (Karine Silva Sobrinho/Terena - curso de Pedagogia - UEMS). 
A educação superior indígena é, certamente, um projeto social e político que se insere numa perspectiva de construção e sedimentação da busca dos povos indígenas por reconhecimento de suas especificidades culturais. Nesses depoimentos fica clara, particularmente no caso do professor Eliel Benites, a percepção da importância da universidade ao mesmo tempo em que ressalta a centralidade da cultura e da afirmação identitária, sem a qual, a presença indígena no Ensino Superior seria mais um elemento de reafirmação da discriminação e homogeneização cultural.

\section{Considerações finais}

Ao final dessa reflexão, podemos afirmar que a presença de jovens indígenas na educação superior indígena é, certamente, um projeto mais amplo, que tem a ver com povos e não apenas com projetos individuais. No entanto essa luta por autonomia e respeito à diversidade cultural desses povos só será possível se houver o devido respeito ao princípio da autodeterminação, e uma busca constante por uma educação específica, de qualidade e intercultural não só para as atuais, mas para as futuras gerações de crianças, jovens e adultos indígenas.

As demandas dos povos indígenas por ensino superior refletem, claramente, as contingências da experiência histórica vivida. Buscam fortalecer os seus conhecimentos tradicionais, sua história e língua e, ao mesmo tempo, o necessário domínio dos assim denominados conhecimentos universais, considerados necessários para uma melhor inserção no entorno regional, e relevante para os seus projetos de autonomia.

O risco é que as Universidades, em seus projetos de ensino superior para os povos indígenas, sigam passando ao largo dos processos mais amplos de busca de autonomia das populações indígenas e centrem sua preocupação apenas em permitir o acesso dos índios aos seus ambientes acadêmicos, o que é, certamente, muito pouco.

Não se trata de questionar o direito dos povos indígenas ao ensino superior, mas das Universidades se perguntarem sobre o tipo de ensino que oferecem aos povos indígenas. Entendo que o desafio está posto, antes de mais nada, para as Universidades, no sentido de repensar e construir novas concepções de ensino que, superando a fragmentação e questionando o saber academicamente sedimentado e hegemônico, que perpassa e está subjacente em nossas práticas pedagógicas, possam permitir o "exercício constante da interculturalidade" em todas as abordagens da realidade (Brand, 2005).

A Universidade, ao abrir espaço para o desafio de contribuir com a busca de novos caminhos de sustentabilidade desses povos, deverá estar 
aberta, também, para essa dimensão da diversidade de perspectivas de futuro, visualizadas pelas populações indígenas.

Por isso as propostas de ensino superior, a exemplo do ensino fundamental e médio, devem caracterizar-se pela porosidade, permeabilidade e flexibilidade, abrindo espaço, especialmente, para a pesquisa, exigência para que seja possível a interculturalidade e a "bricolagem" (Gruzinski, 2001, p. 110), permitindo aos alunos índios esse constante "ajustar (de) peças entre si díspares, reorganizando-as e dando-lhes um sentido" (Gruzinski, 2001, p. 196).

Terão as Universidades engajadas em programas de acesso dos povos indígenas ao ensino superior disposição e condições de transformar os espaços acadêmicos em espaços de diálogo entre saberes, garantindo aos índios amplo apoio para a pesquisa, superando resquícios de longos anos de regime tutelar que marcou a relação com os povos indígenas?

A presença dos jovens indígenas nas universidades, entendendo estas como espaços propícios para serem formadoras de atitudes interculturais, parece ser o acontecimento emergente no processo de tornar nossa sociedade mais traduzível, em meio às suas diferenças. Os indígenas, dessa forma, acabam contribuindo para práticas acadêmicas mais democráticas e para o compromisso de superar a tendência homogeneizadora da educação.

\section{Referências}

AGUILERA URQUIZA. Antonio Hilario. Educação indígena e sustentabilidade: questões para a antropologia. In: Anais da ABA, Goiânia, 2006.

BARTH, Fredrik. Guru, o iniciador e outras variações. Rio de Janeiro: Contra Capa, 2000.

BHABHA, Homi K. O local da cultura. Belo Horizonte: Editora da UFMG, 1998.

BRAND, Antonio. Autonomia e globalização, temas fundamentais no debate sobre educação escolar indígena no contexto do MERCOSUL. In: Série-Estudos. Periódico do Mestrado em Educação da UCDB, Campo Grande, MS, n. 7, abr. 1999.

Indígenas no ensino superior ou ensino superior indígena: experiências e perspectivas. In: Anais do 15 COLE, Campinas, 2005.

. Formação de professores indígenas em nível superior. In: Quaestio - Revista de Estudos de Educação, Sorocaba, SP, v. 8, n. 1, p. 73-82, maio 2006.

BRAND, Antonio; NASCIMENTO, Adir C. Os povos indígenas nas instituições de educação superior e os desafios da sustentabilidade e da autonomia. In. GALVÃO, A. C. T.; SANTOS, G. L. (Orgs.). Educação: tendências e desafios de um campo em movimento. Brasília, DF: Liber Livro Editora/ANPED, 2008. v. 2.

CANCLINI, Néstor García. Culturas híbridas: estratégias para entrar e sair da modernidade. São Paulo: Editora USP, 2003. 
GRÜMBERG, George. Lãs experiências com uma maestria em Antropologia social em um contexto multiétnico y com uma amplia participación indígena: MAS de URACCAN, Bilwi, Región Autônoma del Atlántico Norte (RAAN), Nicarágua. In: Revista Tellus, Campo Grande, MS, ano 5, n. 8/9, p. 73-78, 2005.

GRUZINSKI, Serge. O pensamento mestiço. Tradução por Rosa Freire d'Aguiar. São Paulo: Companhia das Letras, 2001.

HALL, Stuart. Identidade cultural na Pós-modernidade. São Paulo: DP\&A, 2006.

LITTLE, Paul. E. Etnoecologia e direitos de povos: elementos de uma nova ação indigenista In: Etnodesenvolvimento e políticas públicas: bases para uma nova política indigenista. Rio de Janeiro: Contra Capa Livraria, 2002.

LÓPEZ, Luis Enrique. Prefácio. In: CARIMAN, Geraldine Abarca. Rupturas y continuidades en la recreación de la cultura mapuche en Santiago de Chile. La Paz/Bolivia: Plural Editores, 2005. p. 11-14.

MIGNOLO, Walter D. Histórias locais/projetos globais: colonialidade, saberes subalternos e pensamento liminar. Belo Horizonte: Editora UFMG, 2003.

NASCIMENTO, Adir C. Populações indígenas, universidade e diferença. In: Anais da ANPED - Centro-Oeste. Cuiabá, 2006.

OLIVEIRA FILHO, João Pacheco. Seminário: Desafios para uma educação superior para os povos indígenas no Brasil: políticas públicas de ação afirmativa e direitos culturais diferenciados - Hotel Nacional / Brasília - Relatórios de Mesas e Grupos outubro de 2004.

POMPA, Cristina. Religião como tradução: missionários, Tupi e Tapuia no Brasil colonial. Bauru, SP: EDUSC/ANPOCS. 2003.

Programa Rede de Saberes - Relatórios do Levantamento dos Acadêmicos Indígenas nas IES de MS. Campo Grande: UCDB, 2006; 2009.

\section{Recebido em 24 de janeiro de 2011}

Aprovado para publicação em 10 de maio de 2011 
